\title{
Optimization of Texture in Sorghum Ice Cream Cone Production Using Sensory Analysis
}

\author{
J. Kigozi ${ }^{1, *}$, N. Banadda ${ }^{1}$, Y. Byaruhanga ${ }^{2}$, A. Kaaya ${ }^{2}$ and L. Musoke ${ }^{2}$ \\ ${ }^{I}$ Department of Agricultural and Bio-Systems Engineering, Makerere University, P.O. 7062 Kampala, Uganda \\ ${ }^{2}$ Department of Food Technology and Nutrition, Makerere University, P.O. Box 7062 Kampala, Uganda
}

\begin{abstract}
As consumers we are all acutely aware of the texture when we eat or drink solids or liquids and there can no doubt that texture is an important determinant of food quality. Results from the development of the process for sorghum based cones suggested the importance of optimizing the appearance and texture in future studies in the cone development for better consumer acceptance. In this study sensory analysis was used to determine differences in the product texture due to changes in the formulation for fifteen different formulations for the sorghum cones; in view of optimizing the sorghum cone texture. The sensory panel was used to determine the texture rated according to hardness, crispness and overall acceptability. Panelists used a 6-point scale for sensory evaluation ( $6=$ "extremely hard" to $1=$ "soft") to rate hardness and $6=$ "extremely crispy" to $1=$ "Not crispy" to rate crispness and a 9-point hedonic scale (9 = "like extremely"; 1 = "dislike extremely") to rate the overall acceptability. Cones formulations which ranked higher; 8.25 and 8.06 respectively than the control 7.5 in consumer acceptance where F14 (where the sorghum was decreased by $25 \%$ ) and F9 (where water was decreased by 14\%). Formulation F14 which resulted in the best texture was thus be selected and adopted as the formulation for the sorghum ice cream cones.
\end{abstract}

Keywords: Ice cream cones, optimization, sorghum, texture.

\section{INTRODUCTION}

Today's consumers are discerning, demanding and more knowledgeable about food and expect products which are safe, of good value and of high sensory quality [1]. Therefore knowing consumers preferences and perceptions of the sensory characteristics for texture is very important for a food production process. Texture can be measured by sensory or instrumental methods. Results from the development of the sorghum cones showed that for the sorghum cone, appearance $(r=0.856)$ and texture $(r=0.806)$ were most strongly $(P<0.05)$ correlated to overall acceptability. These results suggested the importance of optimizing the appearance and texture in future studies in the cone development. The texture of an ice cream cone is most importantly described by consumers as its crispness [2]. However its meaning is imprecise and varies, nevertheless it is agreeable to that crispy products are mechanically brittle, producing a typical sound at fracturing [3-5]. In this study sensory analysis was used to determine differences in the product texture (hardness, crispness and overall acceptability) due to changes in the formulation for the sorghum cones; in view of optimizing the sorghum cone texture. A trained panel was used for the analysis.

*Address correspondence to this author at the Department of Agricultural and Bio-Systems Engineering, Makerere University, P.O. 7062 Kampala, Uganda; Tel: ????????????; Fax: ??????????????;

Email:jbulyakigozi@yahoo.com

\section{MATERIALS AND METHODS}

\subsection{Material Selection}

Dry Epuripur sorghum was obtained from Victoria seeds, Uganda. The grain was cleaned and sorted to remove any spoilt grain and any other foreign particles. It was milled using a Wonder mill at the highest level of fineness producing whole sorghum flour mean of particle size $120 \mu \mathrm{m}$. Commercial wheat flour (Bakhresa Grain Milling (U) LTD, Uganda) randomly sampled from the open market was purchased and used for the control. Other ingredients such as sugar (Kakira Sugar Works, Uganda), corn starch (American Garden Products, U.S.A), oil (Bidco Uganda Ltd, Uganda), sodium metabisulphite (NORBRIGHT IND, CO.LTD, China), sodium bicarbonate (BIDCO oil Refineries, Kenya), ammonium bicarbonate DESBRO (U) LTD, Uganda) were also randomly purchased from the local supermarkets. The ingredients were used to prepare sorghum ice cream cones of varying formulations.

\subsection{Recipe Formulation}

The recipe used was according to Kigozi et al., (2011) and the ingredients were varied to comprise 13 different formulations (F1: F14) as shown in Table 1. Formulation 1 (F1) comprised the recipe according to Kigozi et al., 2011 [6]; $200 \mathrm{~g}$ sorghum, $60 \mathrm{~g}$ maize starch as a binder, $40 \mathrm{~g}$ sugar, $3 \mathrm{~g}$ leavener (sodium bicarbonate), $3.64 \mathrm{~g}$ lecithin, 8 $\mathrm{ml}$ oil, $350 \mathrm{ml}$ water, $2 \mathrm{~g}$ salt and $1 \mathrm{~g}$ sodium metabisulphite. The other twelve formulations (F2: F14) comprised a $12.5 \%$ 
Table 1. Cone formulations.

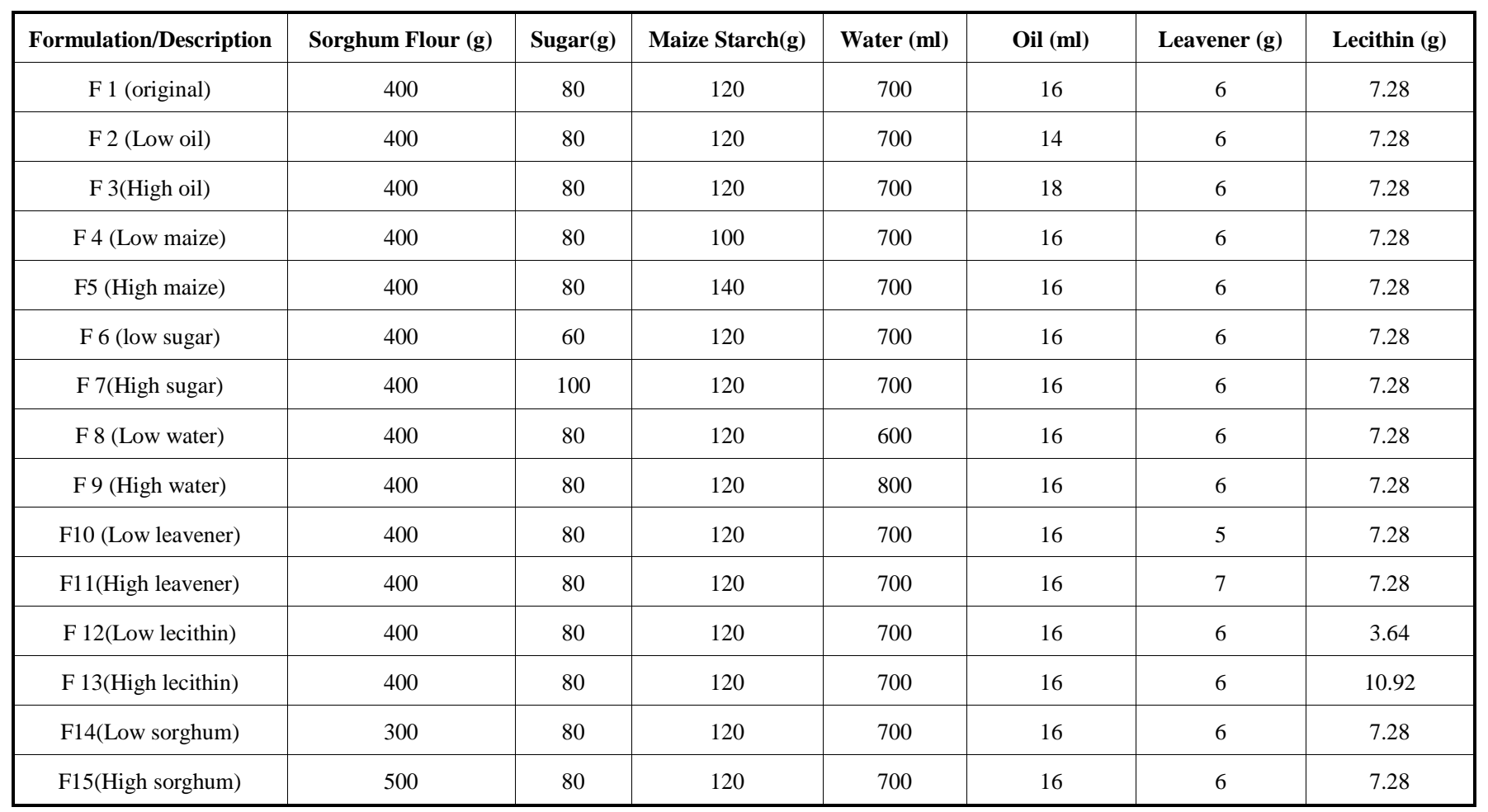

increase or decrease in oil, a $12.5 \%$ increase and decrease in lecithin, a $14 \%$ water increase or decrease in water, a $25 \%$ increase or decrease in sugar, a $16.7 \%$ increase or decrease in leavener, a $16.7 \%$ increase or decrease in maize starch and $25 \%$ decrease in sorghum, while keeping the amounts of other ingredients constant. The resulting batters were baked using a cone making machine at $125^{\circ} \mathrm{C}$ for the lower mould and $175^{\circ} \mathrm{C}$ for the upper mould which temperatures were determined experimentally and yielded the best end product. Dry ingredients were all first measured into a bowl and oil, lecithin, water added and mixing done using a hand mixer (Make: Philips Model HR1456) at low speed until all ingredients were well mixed to form a batter.

\subsection{Determination of the Baking Time}

Preliminary experiments were done at constant baking time but it was realized that some cones did not attain readiness indicative that the variation in ingredients had an effect on the baking time. The baking time in minutes for each of the cone formulations was measured in three replicates using a stop clock. The clock was set to zero and started as soon as the batter was poured into the ice cream cone baking machine. End of baking was determined when the cones started browning and the clock stopped.

\subsection{Determination of Ice Cream Permeability}

The ice cream permeability for cones baked from each of the fourteen cone formulations was determined. Ice cream permeability was measured as the time taken for ice cream to permeate through a given cone. Ten ice cream cones were set on test tube racks and loaded with soft serve ice cream. The time taken for the ice cream to permeate to the outside of the cone was measured in minutes and recorded as the ice cream permeability of the cone.

\subsection{Sensory Analysis}

A trained consumer test panel $(n=8)$ was recruited from the school of Food Technology, Nutrition and BioEngineering, Makerere University by polite solicitation. Panelists were selected based solely on interest, time availability, and lack of allergies to food products used in the study from a pool of 30 people and trained to identify differences in texture in the ice cream cones. The sensory panel was used to determine the texture rated according to hardness, crispness and overall acceptability. Panelists used a 6-point scale for sensory evaluation $(6=$ "extremely hard" to $1=$ "soft") to rate hardness and $6=$ "extremely crispy" to $1=$ "Not crispy" to rate crispness. Panelists used a 9-point hedonic scale ( 9 = "like extremely"; 8 = "like very much"; 7 = "like moderately"; 6 = "like slightly"; $5=$ "neither like nor dislike"; 4 = "dislike slightly"; 3 = "dislike moderately"; 2 = "dislike very much"; 1 = "dislike extremely") to rate the overall acceptability [7].

\subsection{Data Analysis}

Means and standard deviations were calculated for each of the sensory attributes Consumer panel results were also analyzed using LSD for significance of mean differences compared to the control (F1) using SPSS 15.0. All analysis tests were performed at a significance level of 0.05 . 


\section{RESULTS AND DISCUSSION}

Table 2 shows the results from the sensory analysis as well as the baking time of the cones. A decrease of $16.7 \%$ in maize starch and $14 \%$ increase in water resulted in a significant reduction in the mechanical hardness while $25 \%$ increase in sugar and a $14 \%$ decrease in water resulted in significant increase in the hardness of the cone. $12.5 \%$ decrease in oil , and $25 \%$ decrease in sorghum resulted in significant increase, in the crispness and overall acceptability while a $16.7 \%$ increase in maize starch, $25 \%$ increase in sugar resulted in significant decrease in the crispness and overall acceptability. These changes can be explained by the fact that a decrease in the ratio of starch to water results in a structure that is more densely packed due to incomplete gelatinization, with some of the starch remaining in the native form, and is harder and less crispy at the end of baking, the reverse also being true. This agrees with Hadiyanto et al., (2006) that crispness is dependent on gelatinization which in turn is dependent on availability of water. The decrease in crispness due to increase in sugar is because sugar competes with the water for gelatinization [9, 10] Also according to Hadiayanto et al., (2006) [8] that lipids are hardly affected during baking but they affect softness, crispness and staling. As a result, $16.7 \%$ increase in maize starch, $25 \%$ increase in sugar, $16.7 \%$ decrease in leavener, $14 \%$ decrease in water and $12.5 \%$ increase in lecithin resulted in a decrease in the overall acceptability of the cone.

Cones formulations which ranked higher than the control (7.5) in consumer acceptance were those where the sorghum was decreased by $25 \%(8.25)$ and water decreased by $14 \%$ (8.06) this being because more water was availed thus increasing the extent of gelatinization. Decrease in oil also resulted in an increase in the consumer liking because high levels of oil soften the cone structure. Baking time was also decreased by increase in sugar, lecithin, water, maize starch and decrease in the water and the oil implying that these formulations can save on energy as compared to the control. Increase in sugar concentration results in quicker browning due to the milliard reaction and thus a reduction decrease in baking time [10-12]. Although formulation 14 and 9 gave cones that were accessed better for texture than the control, formulation 14 could not hold ice cream for long enough for ice cream (10 minutes) (Table 6-2) to be eaten which is about 18 minutes (Kigozi, 2011). Formulation 9 yielded was able to hold ice cream for long enough for ice cream

\section{CONCLUSION}

In this study sensory analysis was used to determine differences in the product texture (hardness, crispness and overall acceptability) due to changes in the formulation for the sorghum cones; in view of optimizing the sorghum cone texture. A trained panel was used for the analysis. Cones formulations which ranked higher than the control (7.5) in consumer acceptance were those where F14 where the sorghum was decreased by $25 \%(8.25)$ and F9 where water was decreased by $14 \%$ (8.06). Cones from formulation F14 which had the best texture compared to the control when checked for ice cream permeability were found to be too weak. They crumbled within 10 minutes. Cones from

Table 2. Sensory attributes and overall acceptability of Ice cream cones as rated by 8 trained panelists.

\begin{tabular}{|c|c|c|c|c|c|}
\hline Formulation & Hardness $^{\mathrm{a}} \boldsymbol{\mu}(\mathrm{SD})$ & Crispness $^{\mathrm{b}} \mu(\mathrm{SD})$ & Overall acceptability ${ }^{\mathrm{c}} \boldsymbol{\mu}(\mathrm{SD})$ & Ice cream permeability (min) & $\begin{array}{l}\text { Baking time } \\
\quad(\min )\end{array}$ \\
\hline F 1 (original) & $3.75(0.46)$ & $4.38(0.74)$ & $7.50(0.92)$ & 22.0 & 6.5 \\
\hline F 2 (Low oil) & $4.00(0.53)$ & $4.13(0.83)$ & $7.11(0.92)$ & 28.6 & 5.5 \\
\hline F 3 (High oil) & $3.22(0.67)$ & $3.00(0.00)$ & $6.00(0.00)$ & 35.54 & 6.15 \\
\hline F 4 (Low maize) & $2.75(0.70)^{*}$ & $4.38(0.74)$ & $7.25(1.28)$ & 20.0 & 6.25 \\
\hline F5 (High maize) & $4.75(0.75)$ & $2.75(0.89)^{*}$ & $5.00(0.00)^{*}$ & 49.3 & 5.0 \\
\hline F 6 (low sugar) & $3.06(0.56)$ & $4.50(0.93)$ & $7.60(0.74)$ & 21.0 & 6.25 \\
\hline F 7(High sugar) & $4.75(0.71)^{*}$ & $2.75(0.71)^{*}$ & $5.00(0.00)^{*}$ & 60.03 & 5.5 \\
\hline F 8 (Low water) & $4.88(0.64)^{*}$ & $2.63(1.19)^{*}$ & $4.50(2.61)^{*}$ & 60.05 & 5.5 \\
\hline F 9 (High water) & $2.75(0.88)^{*}$ & $4.88(0.83)$ & $8.06(0.78)$ & 19.2 & 5.0 \\
\hline F10 (Low leavener) & $3.67(0.87)$ & $3.44(0.88)^{*}$ & $5.94(1.18)^{*}$ & 44.7 & 6.5 \\
\hline F 11(High leavener) & $3.38(1.18)$ & $4.50(0.00)$ & $7.28(0.0)$ & 25.0 & 5.0 \\
\hline F 12(Low lecithin) & $4.22(0.99)$ & $4.00(1.10)$ & $6.63(0.52)$ & 57.0 & 5.67 \\
\hline F 13(High lecithin) & $3.25(1.28)$ & $3.63(1.10)$ & $6.25(0.88)$ & 35.2 & 4.5 \\
\hline F14 (low sorghum) & $3.00(0.75)$ & $5.13(0.83)$ & $8.25(0.71)$ & 10.10 & 5.0 \\
\hline
\end{tabular}

aScale for Hardness: Range 6= "extremely hard" to 1 = "soft"

"Scale for Crispness: Range 6 = "extremely crispy" to $1=$ "not crispy"

"Scale for overall acceptability $9=$ "like extremely" to $1=$ "dislike extremely"

*Significantly different from the control at a 0.05 level of significance 
formulation F9 with an ice cream permeability of 19.2 minutes were therefore selected as the best cones overall and were thus recommended for piloting in the food industry.

\section{CONFLICT OF INTEREST}

The authors confirm that this article content has no conflict of interest.

\section{ACKNOWLEDGEMENTS}

We would like to express our thanks to Mr. Lammeck Musoke and Mr. Vincent Ddamulira for their technical assistance during laboratory analyses. Special thanks go to the Carnegie Cooporation Newyork under the NGAA project who have funded this research.

\section{REFERENCES}

[1] Hashmi I. Sensory Evaluation Techniques. $18^{\text {th }}$ Annual IOAM Conference (MEA District), Muscat Oman. 2007

[2] Huang VT, Luebber, ST, Lindamood JB, Hansen PMT. Ice cream cone baking ; 2. Textural characteristics of rolled sugar cones. Food Hydrocolloid 1989; 3(1): 41-55.

[3] Chen J, Karlsson C, Povey M. Acoustic Enveloppe detector for crispness assessment of biscuits. J Text stud 2005; 36: 139-56.
[4] Luyten H, Plitijer JJ, Vliet TV. Crisp/crunchy crusts of cellular foods: a literature review with discussion. J Text stud 2004; 35 (5): 445-92.

[5] Bourne, M. Food texture and viscosity, Concept and measurement. $2^{\text {nd }}$ Ed., Academic press, San Diego, CA, 2002.

[6] Kigozi J, Byaruhanga YB, Kaaya A, Banadda N. The development of the production process of Sorghum based sorghum cones. J food Technol 2011; 9(6): 143-9.

[7] Ramcharitar A, Badrie N, Mattfeldt-beman M, Matsuo H, Ridley C. Consumer Acceptability of muffins with flaxseed (Linum usitatissimum). J Food Sci 2005; 70 (7): s504-7.

[8] Hadiyanto DC, Asselman A, van Straten G, Boom RM. Esveld DC, van Boxtel AJB. Quality prediction of bakery products in the initial phase of the design process. Innovative Food Sci Emerg Technol 2006; 8 (2): 1527-34.

[9] Manohar RS, Rao PH. Effect of sugars on the rheological properties of biscuit dough and quality of biscuits. J Science Food Agri 1997; 75: 383-90.

[10] Cauvin SP, Young LS. Baked products: Science technology and practice. Blackwell Publishing Ltd, UK Calvalho CWP, Mitchell J r. effect of sucrose on starch conversion and glass transition on non-expanded maize and wheat extrudates. Cereal Chem 2001; 78: 342-8.

[11] Mundt S, Wedzicha BL. A kinetic Model for browning in the baking of biscuits: Effects of water activity and temperature. SciDirect LWT 2007; 40(6): 1078-82.

[12] Purlis E. Baking process design based on Modelling and simulation: Towards optimization of bread baking. Food control 2012; $27: 45-52$.

(C) Kigozi et al.; Licensee Bentham Open.

This is an open access article licensed under the terms of the Creative Commons Attribution Non-Commercial License (http://creativecommons.org/licenses/ by-nc/3.0/) which permits unrestricted, non-commercial use, distribution and reproduction in any medium, provided the work is properly cited. 